December 2006

\title{
Feedback (F) Fueling Adaptation (A) Network Growth (N) and Self- Organization (S): A Complex Systems Design and Evaluation Approach to Professional Development
}

\author{
Susan A. Yoon \\ University of Pennsylvania, yoonsa@gse.upenn.edu \\ Eric Klopfer \\ Massachusetts Institute of Technology
}

Follow this and additional works at: https://repository.upenn.edu/gse_pubs

\section{Recommended Citation}

Yoon, S. A., \& Klopfer, E. (2006). Feedback (F) Fueling Adaptation (A) Network Growth (N) and SelfOrganization (S): A Complex Systems Design and Evaluation Approach to Professional Development. Retrieved from https://repository.upenn.edu/gse_pubs/53

Postprint version. Published in Journal of Science Education and Technology, Volume 15, Issues 5-6, December 2006, pages 353-366.

Publisher URL: http://dx.doi.org/10.1007/s10956-006-9024-4

This paper is posted at ScholarlyCommons. https://repository.upenn.edu/gse_pubs/53

For more information, please contact repository@pobox.upenn.edu. 


\title{
Feedback (F) Fueling Adaptation (A) Network Growth (N) and Self-Organization (S): A Complex Systems Design and Evaluation Approach to Professional Development
}

\begin{abstract}
This paper reports on the efficacy of a professional development framework premised on four complex systems design principles: Feedback, Adaptation, Network Growth and Self-organization (FANS). The framework is applied to the design and delivery of the first two years of a three-year study aimed at improving teacher and student understanding of computational modeling tools. We demonstrate that structuring a professional development program around the FANS framework facilitates the development of important strategies and processes for program organizers such as the identification of salient system variables, effectively distributing expertise, adaptation and improvement of professional development resources and activities and building technological, human and social capital. For participants, there is evidence to show that the FANS framework encourages: professional goal setting, engagement in a strong professional community and personal autonomy by enabling individualized purpose-all fundamental components in promoting self-organization. We discuss three meta-level themes that may account for the success of the FANS framework: structure vs. agency, exploration vs. exploitation and short-term vs. long-term goals. Each illustrates the tension that exists between competing variables that need to be considered in order to work effectively in real world complex educational systems.
\end{abstract}

\section{Keywords}

complex systems, educational technology, professional development

\section{Comments}

Postprint version. Published in Journal of Science Education and Technology, Volume 15, Issues 5-6, December 2006, pages 353-366.

Publisher URL: http://dx.doi.org/10.1007/s10956-006-9024-4 
JOST Tracking \#2005-73-Yoon

Authors:

Susan A. Yoon

University of Pennsylvania

Eric Klopfer

Massachusetts Institute of Technology

Contact Author's Email:

yoonsa@gse.upenn.edu

FINAL VERSION 
Running head: A COMPLEX SYSTEMS DESIGN AND EVALUATION APPROACH TO PROFESSIONAL DEVELOPMENT

Feedback (F) Fueling Adaptation (A) Network Growth (N) and Self-Organization (S): A Complex Systems Design and Evaluation Approach to Professional Development

\author{
Susan A. Yoon \\ Graduate School of Education \\ University of Pennsylvania \\ 3700 Walnut Street \\ Philadelphia, PA 19104 \\ Tel 215.746.2526 \\ Fax 215.898.4399 \\ Email yoonsa@gse.upenn.edu \\ Eric Klopfer \\ Teacher Education Program \\ Massachusetts Institute of Technology
}

To Appear in the Journal of Science Education and Technology 


\section{ABSTRACT}

This paper reports on the efficacy of a professional development framework premised on four complex systems design principles: Feedback, $\underline{\text { Adaptation, }}$ Network Growth and $\underline{\text { Self- }}$ organization (FANS). The framework is applied to the design and delivery of the first two years of a three-year study aimed at improving teacher and student understanding of computational modeling tools. We demonstrate that structuring a professional development program around the FANS framework facilitates the development of important strategies and processes for program organizers such as the identification of salient system variables, effectively distributing expertise, adaptation and improvement of professional development resources and activities and building technological, human and social capital. For participants, there is evidence to show that the FANS framework encourages: professional goal setting, engagement in a strong professional community and personal autonomy by enabling individualized purpose-all fundamental components in promoting self-organization. We discuss three meta-level themes that may account for the success of the FANS framework: structure vs. agency, exploration vs. exploitation and short-term vs. long-term goals. Each illustrates the tension that exists between competing variables that need to be considered in order to work effectively in real world complex educational systems.

\section{KEY WORDS}

Complex Systems, Educational Technology, Professional Development 


\section{INTRODUCTION AND STUDY GOALS}

The complexity of implementing educational change has been a recent focus of many educational leaders interested in understanding how curricular and pedagogical reform efforts can have a scalable, enduring impact in educational systems. In his Change Forces series focused on reform, Fullan (1993, 1999, 2003) uses complex systems theory as an organizing framework to reveal core concepts such as non-linearity, unpredictability and multi-level agency that are important issues to contend with in real-world educational systems. In reference to the problem of scale, Elmore (1996) writes about the difficulties experienced by nested clusters of innovation when trying to move from local to global contexts. He states that failures, historically, in generating successful large-scale reforms can be attributed to an "absence of practical theory that takes account of the institutional complexities that operate on changes in practice” (p. 21). Coburn (2003) reinforces the idea that educational reform and improvement are matters of complexity stating that problems of scale stem from the inability of research to address the inherent multidimensionality between and within classrooms, schools and districts. She contends that better research designs must be utilized to capture a more complex vision.

In addition, a growing body of research in the learning sciences has highlighted further layers of complexity when educational reform is driven by the use of educational technologies. Fishman et al., (2004) discuss difficulties in implementation that arise when computer access is viewed from the perspective of sustainability of innovations. They suggest that few cognitively oriented learning technologies have found their way into regular mainstream practice due to gaps that exist between culture, capability and policy norms operating at system levels. Cuban et al., (2002) likewise remark that changes of deeply entrenched systemic organizational and 
operational factors such as how teaching time is allocated, how technical support is provided and how reliable technical tools are, must take place in order to move beyond simple fleeting modifications to practice.

At the core of our work is the belief that a complex systems approach for the design and implementation of an educational improvement program is a prudent undertaking. This paper reports on the results of a research program in which complex systems processes are used to organize, harness and evaluate professional development activities around educational technology tools that teach complex systems modeling. Described in greater detail below, the proposed complex systems approach is applied to a comprehensive large-scale NSF-funded project under the program title Information Technology Experiences for Students and Teachers (ITEST). This NSF program is designed to increase opportunities for students and teachers to learn and apply information technology concepts and skills in the STEM content areas (science, technology, engineering and mathematics). Our project, entitled New Mexico Adventures in Modeling, aims to achieve the broader ITEST goals through scientific and computational investigations using tools that simulate complex systems. It should be noted that although the content and tools used as the subject matter of professional development activities, in this study, focus on learning about complex systems, the professional development framework (also premised on complex systems processes) itself can be applied to any content domain. The purpose of the paper is not to produce definitive generalizable claims about how to create a systemic structure that supports scalable innovations. Rather, the purpose of the paper is to document implementation efforts and reveal specific outcomes that highlight the efficacy of a complex systems-informed professional development research design. The hope is that, as 
Goldman (2005) writes, "Improved understanding of circumstances that facilitate and impede change can be fed into the design of future efforts to promote and sustain educational improvements” (p. 70).

\section{THEORETICAL CONSTRUCTS}

Complex systems can be found in all aspects of our world. They span the relatively micro scale of structures and behaviors such as molecules of water organizing to form vortices in fast running rivers or the single fertilized egg developing through embryogenesis to create differentiated cells that eventually become the human form. On more macro scales, schools, businesses, cities, animal populations and ecosystems are also thought of as complex systems. Our understanding of what complex systems are and how they operate also stems from a variety of disciplines ranging in scope and diversity from physics and chemistry to biology, sociology and economics. Several interdisciplinary research organizations such as the Santa Fe Institute have convened some of this century's most accomplished scientists and social scientists who are devoted to advancing our understanding of what is collectively termed complex systems science.

The search for universal principals that can describe and unify these seemingly disparate domains is ongoing and the approaches used are as varied as the disciplines from which they originate. Many important inroads have been made in the field, however, that suggest unification of our knowledge is not far off (Bar-Yam, 1997). Despite variation in physical components or agents, complex systems can be generally defined as existing when any given number of interconnected elements, parts or individuals, communicate in non-linear ways. The patterns of interactions form a collective network of relationships that exhibit emergent properties that are 
not observable at subsystem levels. When perturbations occur, the network self-organizes in, often unpredictable ways where new properties can emerge. In other words, the behavior of the system cannot be accurately determined by simply observing the behavior of the parts. The manner in which complex systems communicate, respond to perturbations and self-organize is understood by studying the dynamical processes through which they evolve over time. Acquiring information from their environment through feedback, complex systems identify regularities in that information and use this to modify behavior in the real world (Gell-Mann, 1994). In this way, they are said to be adaptive.

In sum, complex systems can be thought to exist and operate through four critical elements: networks of interconnected individuals and systems, self-organization, adaptation and feedback. Although these elements have been largely identified through observations of existing complex systems, complex system processes can also be used to inform research with the goal of designing structures and strategies to improve the success of organizations. For example, in the field of management, Sterman (2000) has applied systems dynamics processes to create modeling tools that improve managerial decision-making in corporate and economic systems. Senge (2000) discusses methods in which institutions of learning can become learning organizations through individual and collective goal setting and reflection. Similarly, using evolutionary dynamics, Axelrod and Cohen (1999) offer insight into how complexity within social organizations can be harnessed by deliberately changing the structure of a system to improve performance.

\section{METHODOLOGY}




\section{Professional Development Framework}

\section{The Program}

Although studies on complex systems have recently gained increasing exposure and popularity (Capra, 1996; Holland, 1998; Kauffman, 1995; Johnson, 2001), they have yet to inform educational practices in any appreciable way. In order to address this, over the last few years, we have conducted teacher workshops structured around two modeling tools called StarLogo (Colella \& Klopfer, 2000)—a desktop computer application that allows users to design, build, and analyze agent-based complex systems simulations and Participatory Simulations (Klopfer et al., 2005)—handheld computer games that allow users to become embedded agents in the complex system. Previous research efforts were channeled into creating stable modeling tools and developing accompanying curriculum materials (Colella et al., 2001). In the present study, we were interested in understanding how the modeling tools and curriculum materials could be applied in regular school classrooms. A number of activities/experiences encompassed the initial professional development program with our teacher participants:

1. A 10-day 60 hour intensive summer workshop

2. Bi-monthly whole group face-to-face meetings

3. Access to local expert facilitators

4. Communication of a shared on-line bulletin board

Results reported here document the first two years of a three-year implementation.

\section{Participants}

47 middle and high school teacher participants were recruited from school districts in a mixed urban-rural area in the southwestern part of the U.S. Teachers were recruited to participate in 
either the 2003-2004 (Cohort 1) or 2004-2005 (Cohort 2) academic school years. Teaching subjects included Mathematics, Earth Science, Biology, General Science Social Science, Computers and English. Computer programming skills and complex systems understanding ranged from expert to novice. Of the 47 teachers recruited, $43 \%$ were female and $57 \%$ were male, half had a masters degree or higher, 45\% taught less than 6 years, 19\% taught between 6 10 years and $36 \%$ had greater than 10 years experience. The instructional team consisted of three local facilitators and three research investigators.

Following on the other previously mentioned research programs in domains outside of education, a framework was constructed using the four elements of Feedback, Adaptation, Network growth and Self-organization (FANS) as design principles to inform the scope and sequence of professional development activities in the ITEST project. The design principles were conceptualized to be dynamic and progressive, building from each other and ultimately looping back to the origin of feedback. In other words, feedback is used to inform the kinds of adaptations needed, which are, in turn, used to foster network growth and self-organization after which the whole process recapitulates. Since the application and goal of each principle is slightly different, the data sources and types of analyses differ across the four types. For example, the principle of network growth is less about applying interventions and more about observing whether it has improved (although, there is some intervention involved). Each principle and its application in the study are described in further detail in the sections below.

\section{Design Principles}




\section{Feedback.}

Feedback generally refers to the process by which information from the output of a system is returned to the original source. Thermostats in heating and cooling systems work by triggering mechanisms that adjust the temperature based on the feedback input received from the surrounding environment. In social group activity, the self-correcting behavior of group members is often influenced by feedback that indicates divergence from group norms (Arrow et

al., 2000). Feedback is an important process that both explains system functioning and also coordinates and regulates system structures and behaviors. In the FANS framework, the design principal of feedback is used to gather information about how the professional development community is operating at every stage of the project. Continuous and multiple data collection techniques and tools are used to formatively evaluate the success of the program at specific instances in time. This feedback information is used as starting points for the redesign and delivery of program activities to influence the alignment of system variables, e.g., individual participant goals with program research goals so that outcomes are mutually beneficial.

\section{Adaptation.}

Attending to mutually beneficial outcomes cannot be achieved without the mechanism of adaptation. From a biological perspective, the ability for organisms to adapt to their changing environment is the arbiter of survival for individuals and populations. Varela (1999) extends the idea of biological adaptation to humans and social systems. He contends that environments and identities are historically constituted, i.e., our ability to function organizes around recurrent patterns of embodied experience as we make transitions from one environment to the next. In cases where human experience cannot cope with a specific environment, we must carefully 
examine the parameters around which such a breakdown occurs in order to seek better strategies. Thus, the second important design principle in the FANS framework is adaptation. In attending to environmental and participant conditions garnered from feedback activities, our program seeks to respond to context-dependent factors that influence individual experiences, as well as curricular and system-wide purposes. Through continuous modifications to program structures and goals, professional development strategies evolve to attempt to meet the needs of all constituents at multiple levels.

\section{Network Growth.}

An important variable to sustaining program activities at multiple levels of implementation also hinges on the ability to reveal and utilize available and potential technological, human and social network capacities. In economics, the term "capital” generally refers to accumulated financial wealth that can be used to procure additional income or wealth. Technological and human capacities can be thought of in terms of physical capital (physical objects) and human capital (properties of individuals), whereas, social capital refers to resources one can access through connections amongst individuals (Putnam, 2000). To ensure healthy and productive program maintenance and growth, increasing capacities in the three categories of technological, human and social capital is the third design principal. Collectively referred to as network growth, activities undertaken in the program can be defined in two operational categories—observation and intervention. In the observational category garnered from feedback activities, measures include: taking stock of existing technological facilities; identifying human experiences, talents and skills amongst participants and facilitators; surveying network structures within and between schools such as how teaching teams are constructed and how information is distributed amongst 
administrators; mapping geographical areas that optimize the locus of activity; revealing organizational limits and locating groups that have the potential to assist in overcoming those limits. Intervention measures are then used to address each of the observational measures to adapt program activities, e.g., assigning tasks to individual facilitators according to their particular strengths.

\section{Self-Organization.}

Self-organization refers to the ability of a system to spontaneously adopt new structures and new forms of behavior in order to survive (Capra, 1996). In other words, systems need to exhibit a kind of flexibility to be able to adapt positively to continual change. Self-organization is critically dependent on information received from the environment, i.e., the mechanism of feedback. Without this, it is impossible to know what kind and where in the system, adjustments need to be made. Self-regulation, an important process in self-organization, refers to the ability of a system to identify patterns of behavior, out of its own resources, that indicate which way the system must be tweaked or adapted. In the FANS framework, self-organization and selfregulation are operationalized in several ways. First, program activities and attitudes remain open and flexible. It is expected and anticipated that no two workshops will run the same way and provisions are made to adjust behaviors spontaneously, such as creating an evolving agenda. In order to help coordination efforts, communication structures are used to provide opportunities for collaboration amongst the various program constituents. Finally, efforts are made to encourage self-reflexive metacognitive behavior both at the individual and system level with a view to enhancing teacher autonomy and empowerment. The long-term goal is to facilitate the adoption 
of program ownership, so that motivation to keep the program operational and growing originates from within the system rather than from outside sources.

\section{Data Sources and Data Analyses}

Data sources and collection techniques included: pre/during/post program surveys, assessment of contributions to online community, participant, facilitator and administrator semi-structured interviews, focus group discussions, curriculum plans, researcher/facilitator classroom observations, email exchanges and field notes The intent of the multiple data source collection was to capture as many of the implementation details as possible in order to determine the efficacy of the complex systems professional development framework on program success. Thus, the methodology was qualitative in nature (Lincoln \& Guba, 2000) with the assumption that categories and themes would emerge from the data. Codes, categories and themes for the data set were, for the most part, negotiated amongst the investigator team (Strauss \& Corbin, 1998).

Under the design principle of feedback, we sought to gather information about affordances and barriers to implementation that influenced the success of the professional development community. Program survey questions included both Likert-scale and open-ended questions such as the following: List the top five factors that were the most helpful in the successful implementation of program activities in your classroom; List the top five factors that presented the greatest barriers to the successful implementation of program activities in your classroom; What resources do you feel need to be developed in order to help you participate in the program?; If you plan on attempting a program activity or unit next year, what needs to happen at your school? Individual semi-structured interview questions included: How do you see your 
role as a facilitator and where do you feel you are most effective?; In your opinion, what are the main characteristics that a participating teacher needs to possess in order to be successful in this program? Focus-group discussion questions like-wise probed implementation variables. Email and online exchanges as well as researcher/facilitator fieldnotes were also combed for instances that described implementation variables. 43 variables were identified in total. Further analysis is yet to be completed that rank orders the relative influence of each of the variables. For this study, we were interested in identifying as many different variables as possible in order to attempt a categorization that would help us to understand the nature of implementation in such a way that continual program improvement would be enabled.

A categorization manual was constructed using the categories of structure, function and behavior described in Hmelo (2000). In that study, the categories were used to measure student understanding of complex systems phenomena. We found this to be a useful taxonomic tool to address the complexity of implementation variables. In our framework, structural (S) variables include: rules, physical structures, organization and/or legislation that help or hinder your ability to accomplish a task. Functional (F) variables include: skills, resources, supports, tools and/or student or subject characteristics that help or hinder your ability to accomplish your goals. Behavioral (B) variables include: knowledge, beliefs, attitudes, dispositions, preferences or understanding that help or hinder your ability to accomplish a task. The variables were further divided into micro (I), meso (E), and macro (A) level variables that reflect the organization of educational systems. The micro, meso and macro level categorization has been used in a range of different domains to recognize the existence of multiple nested systems, each of which may have specific organizational structures and goals (Liljenstrom \& Svedin, 2005; Yi-Zhang \& Kim, 
2005). In this study, micro level variables encompass individual teachers and their classrooms; meso level variables encompass multiple teachers within the school or within the Adventures in Modeling project; and macro level variables encompass multiple schools, district-wide activities and beyond. One rater was trained on the implementation variables categorization manual and the entire data set of 43 variables were coded and compared with researcher codes. $90 \%$ interrater reliability was obtained with the four coding discrepancies negotiated until consensus was reached on the specific code to be assigned.

The data and results described for the design principle of adaptation document changes that occurred in seven major project areas collectively determined by project staff from the list of 43 variables obtained through feedback. For network growth and self-organization, the data offers evidence showing the extent to which both design principles improved as revealed in year-end focus group interviews.

\section{RESULTS}

This section is organized by evidence and/or outcomes under each of the four design principles in the FANS framework that illustrate or reveal the evolving nature and success of professional development activities undertaken in the Adventures in Modeling project.

\section{Feedback}

Table 1 shows a topology of affordances and barriers to implementation constructed from the Structure, Function, Behavior-Micro, Meso, Macro (SFB-IEA) taxonomy of the 43 
implementation variables. The topology was used to support program activities in a number of important ways.

\section{Identifying a Propensity Toward Change Hierarchy.}

Surveying the topology of variables allowed the project team to identify which variables were the most difficult, comparatively, within which to facilitate change. Structural variables presented the greatest challenge. For example, the location of computers within a school appeared to be a ubiquitous concern for our participants, many of whom complained about having to waste valuable teaching time tracking down the computer lab manager, reorganizing schedules to accommodate available space, and moving classes between rooms that were often located in different halls or even different buildings. These structural variables were ones that the project team had little control over. The pattern of difficulty also appeared to increase, not surprisingly, moving from micro to macro levels, e.g., from the individual to the school-wide district. Behavioral variables were the next most difficult to work with, however, many of these variables showed small increments of growth as participation in program activities increased over time. For example, teacher's risk-taking thresholds and comfort levels in working with both the desktop and handheld computer simulations improved with successive iterations of classroom implementations. Frequent availability of facilitators and willingness to provide technical, pedagogical and moral support was found to be a key change mechanism. Thus, in terms of behavioral variables, the role of some members of the project team was one of edification, a kind of support or resource that was continuously available as changes in selfefficacy beliefs, for example, emerged. However, similar to structural variables, the locus of control generally existed just outside the purview of the project team. Likewise, the level of 
Table 1 Topology of Affordances and Barriers to Implementation

\begin{tabular}{|l|l|l|l|}
\hline Levels & Structure & Function & Behavior \\
\hline
\end{tabular}




\begin{tabular}{|c|c|c|c|}
\hline Micro & $\begin{array}{l}\text { - individual teaching time } \\
\text { constraints }\end{array}$ & $\begin{array}{l}\text { - a teacher's ability to integrate } \\
\text { AlM activities with the } \\
\text { standard curriculum } \\
\text { - number of years of } \\
\text { experience a teacher has } \\
\text { - a teacher's experience in } \\
\text { previous careers e.g., being a } \\
\text { computer programmer } \\
\text { - a teacher having ready-made } \\
\text { curriculum materials to } \\
\text { implement AIM activities } \\
\text { - a teacher's skill in using } \\
\text { information technology } \\
\text { - the subject domain of a } \\
\text { teacher and grade level } \\
\text { applicability } \\
\text { - a teacher's classroom } \\
\text { management skills } \\
\text { - a teacher's programming } \\
\text { knowledge/skills }\end{array}$ & $\begin{array}{l}\text { - a teacher's self-efficacy beliefs } \\
\text { - a teacher's preferred teaching } \\
\text { style, e.g., student-centered vs. } \\
\text { teacher-centered } \\
\text { - a teacher's level of innovativeness } \\
\text { - a teacher's complex systems } \\
\text { understanding } \\
\text { - a teacher's epistemological beliefs } \\
\text { about teaching } \\
\text { - a teacher's risk-taking threshold } \\
\text { - a teacher's comfort level using } \\
\text { technology }\end{array}$ \\
\hline Meso & $\begin{array}{l}\text { - lack of classroom space to } \\
\text { house computers within the } \\
\text { school } \\
\text { - organization of the school } \\
\text { day within the school } \\
\text { - centralized control of } \\
\text { computer lab, i.e., one } \\
\text { person with the key } \\
\text { - location of computers in the } \\
\text { school, e.g., computer in a } \\
\text { lab vs. computers in each } \\
\text { classroom } \\
\text { - AlM facilitator accessibility, } \\
\text { e.g., how facilitator's have } \\
\text { been organized or allocated } \\
\text { - one vs. several teachers } \\
\text { implementing AIM activities } \\
\text { in a school } \\
\text { - inadequate computer } \\
\text { hardware in a school } \\
\text { - disorganization at the } \\
\text { school level }\end{array}$ & $\begin{array}{l}\text { - a school's demographics, } \\
\text { e.g., economically challenged, } \\
\text { high ESL } \\
\text { - administrator's support within } \\
\text { a school } \\
\text { - quality of AIM instructor } \\
\text { facilitation, e.g., behavior, } \\
\text { energy level, enthusiasm } \\
\text { - face-to-face AIM community } \\
\text { support and collaboration } \\
\text { - on-line AIM community } \\
\text { support and collaboration } \\
\text { - intensive summer workshop } \\
\text { to learn how to implement AIM } \\
\text { activities } \\
\text { - on-going post-summer } \\
\text { workshop support } \\
\text { - one or no technology support } \\
\text { staff available }\end{array}$ & $\begin{array}{l}\text { - teacher envy in a school, e.g., } \\
\text { innovators vs. status quo } \\
\text { - a school's or department's } \\
\text { commitment to or disposition } \\
\text { toward other curricular/instructional } \\
\text { programs } \\
\text { - school culture, e.g., beliefs or } \\
\text { philosophies that encourage } \\
\text { innovation }\end{array}$ \\
\hline Macro & $\begin{array}{l}\text { - other district-wide edicts or } \\
\text { agendas } \\
\text { - insufficient technology } \\
\text { funding at the district level } \\
\text { - district level disorganization } \\
\text { - standardized testing } \\
\text { - No Child Left Behind } \\
\text { legislation }\end{array}$ & $\begin{array}{l}\text { - AIM program connections to } \\
\text { outside educational programs } \\
\text { such as the New Mexico } \\
\text { Adventures in Super } \\
\text { Computing Challenge and Los } \\
\text { Alamos National Labs }\end{array}$ & $\begin{array}{l}\text { - motivation to choose high paying } \\
\text { PD workshops because of low } \\
\text { teacher's salaries in the state } \\
\text { - a districts commitment to or } \\
\text { disposition toward other } \\
\text { curricular/instructional programs }\end{array}$ \\
\hline
\end{tabular}

difficulty in effecting change generally increased as the size of the system increased. Functional

variables were by far the easiest ones to facilitate in terms of working toward improving implementation conditions. Apart from two variables, i.e., number of years of experience a 
teacher has and a teacher's experience in previous careers, the project team had some level of control over all other variables that enabled relatively immediate action. For example, teacher's indicated that they would be more inclined to use StarLogo activities in the classroom if they had ready-made curriculum materials available to them. Therefore, compiling and constructing subject-specific models and curricula became a focal aspect of our professional development workshops where previously, skill in programming and the development of complex systems theoretical understanding took the greatest priorities.

\section{Distributing Expertise.}

Constructing the topology of variables also served as a tool for mapping individual project team member expertise to areas for implementation improvement that best suited their skills and experience. In other words, understanding specific implementation needs enabled us to select from the available bank of expertise and assign activities to the most appropriate project members. For example, due to his previous career experience as a manager for various webbased games and simulations projects one of our lead facilitators assumed the responsibility for the design and construction of the web-based models library. Another facilitator, with 40 years of teaching experience, had worked in various leadership capacities including district-wide technology coordinator, and had an implicit understanding of teacher self-efficacy issues in science and technology classes. She had also developed a vast and intricate educational network in which she could draw on the expertise of former colleagues and make valuable connections between people. She visited several of our struggling teachers to lend moral support and in two cases, through her network of connections, secured extra computers in classrooms that had insufficient hardware to run StarLogo models. Through her work with after school programs in 
the local school district, another of our lead facilitators became well connected with the various middle and high school administrators in the district. Furthermore, because her own children were attending district area schools, she knew exactly when special events were being held, when schools were closed and when teachers would be tied up with other professional commitments. All of this information was very useful in planning, for example, when our key informational open houses would be held to showcase the program to schools and administrators.

\section{Adaptation}

Table 2 shows the timeline of adaptations made to key professional development components in the New Mexico Adventures in Modeling Program. The list of components includes: recruitment; partnerships \& networks; administration; workshops; facilitation structure; curriculum development and communication tools. For each component, descriptions of the adaptations made to program structure and delivery is outlined. Three components are discussed in greater detail below that show the evolution of adaptive professional development strategies.

\section{Workshops.}

Three major goals underpin the program framework: working with teachers to develop and integrate Adventures in Modeling curriculum in their specific content areas; facilitating a shift

toward understanding phenomena from a complex systems perspective; and teaching computational skills to construct, manage and interpret models or simulations. Although all three serve important roles, arguably the most critical of these is the ability to use AIM curricula in the classroom. However, what we found from participant feedback was that learning the StarLogo programming language was the first barrier to entry in terms of teacher self-efficacy beliefs, 
comfort levels and risk-taking thresholds. For a majority of our participants who were novice programmers, this perception became a deterrent for using AIM activities with their students. Consequently, a good portion of workshop instructional time during the first year focused on helping teachers improve programming skills. Yet despite this effort, teachers continued to struggle with this dimension. Obviously some changes needed to be made. According to discussions with facilitators and long-time StarLogo users, there was underrepresented potential and value in exploring uses of existing models. It was revealed that more experienced StarLogo teachers often began with working code and simply made minor modifications to suit the purpose of the particular concept being illustrated. In order to follow this curricular route, however, teachers needed to have a solid understanding of the complex system they wanted to model. The focus of the second summer and follow-up workshops thus shifted to address the latter two of the three major goals. Not coincidentally, the percentage of teachers who incorporated StarLogo activities within the first term of the school year increased from $41 \%$ with Cohort 1 to 65\% with Cohort 2.

\section{Facilitation Structure.}

Initially the program began with three instructional facilitators (tier 1) who had differing levels of responsibilities, time commitments and flexibility in their workday that constrained or enabled participation in the project. The inner-city science teacher for example, could not leave his school during the day to facilitate in another teacher's classroom. After school time was also tied 


\begin{tabular}{|c|c|c|c|c|c|c|c|c|c|c|}
\hline PD Activities & Summer 03 & Fall 03 & Winter 03 & Spring 04 & \multicolumn{2}{|c|}{ Summer 04} & Fall 04 & \multicolumn{2}{|c|}{ Winter 04} & Spring 05 \\
\hline Recruitment & $\begin{array}{l}\text { Main selection criteria for } \\
\text { Cohort } 1 \text { includes: STEM } \\
\text { content areas \& grade } \\
\text { level in the Santa Fe } \\
\text { catchment area }\end{array}$ & & & \multicolumn{3}{|c|}{\begin{tabular}{|l|} 
Selection criteria for Cohort 2 \\
expands to include: Humanities and \\
History content areas, recruitment of \\
individuals within existing schools and \\
administrators/partner organizations. \\
\end{tabular}} & & & \multicolumn{2}{|c|}{\begin{tabular}{|l|} 
Selection criteria for Cohort \\
3 further expands to include \\
technology coordinators and \\
recruitment of grade teams \\
within existing schools. \\
\end{tabular}} \\
\hline \multirow{3}{*}{$\begin{array}{l}\text { Partnerships \& } \\
\text { Networks }\end{array}$} & \multirow{2}{*}{\multicolumn{4}{|c|}{$\begin{array}{l}\text { Strong partnership formed with New Mexico state-wide Super Computing Challenge } \\
\text { (http://www.challenge.nm.org). Chair of the Challenge program is a Cohort } 1 \text { participant. } \\
\text { StarLogo becomes one of two official Challenge programming languages. Other Cohort } 1 \\
\text { participants and facilitators are recruited to work with training and Challenge teams. }\end{array}$}} & \multicolumn{6}{|c|}{$\begin{array}{l}\text { Strength of partnership with the Challenge increases with a growing number of } \\
\text { participants and facilitators overlapping in the two programs. }\end{array}$} \\
\hline & & & & & \multirow{2}{*}{\multicolumn{6}{|c|}{$\begin{array}{l}\text { Partnership schools grow in number from } 15-20 \text {. Five hub schools are formed with } \\
\text { three or more participants and within school facilitation. Other partner organizations } \\
\text { are added to the network such as the Los Alamos National Labs. Educator's Expo is } \\
\text { held to increase organization partnerships and networks. }\end{array}$}} \\
\hline & \multicolumn{4}{|c|}{\begin{tabular}{|l|} 
There are 15 partnership schools including public middle/high schools, private \\
middle/high schools, charter and alternative schools working with our program.
\end{tabular}} & & & & & & \\
\hline Administration & $\begin{array}{l}\text { Very little emphasis is } \\
\text { put on connecting with } \\
\text { administrators. }\end{array}$ & \multirow{2}{*}{\multicolumn{2}{|c|}{\begin{tabular}{|l|} 
Site visits, introductions \\
and meetings are \\
conducted with \\
administrators of \\
partnership schools. \\
\end{tabular}}} & \multirow{2}{*}{\multicolumn{2}{|c|}{\begin{tabular}{|l|} 
Meetings are held with \\
Superintendent of public \\
school and presentations \\
are made to secondary \\
school administrators. \\
\end{tabular}}} & $\begin{array}{l}\text { Furthel } \\
\text { existin } \\
\text { school }\end{array}$ & $\begin{array}{l}\text { e visits are } \mathrm{m} \\
\text { dd new partne } \\
\text { ministrators. }\end{array}$ & $\begin{array}{l}\text { made with } \\
\text { nership }\end{array}$ & \multirow{2}{*}{\multicolumn{2}{|c|}{$\begin{array}{l}\text { Existing and new administrators } \\
\text { are invited to attend the } \\
\text { Educators Expo in which the } \\
\text { work of partnership schools is } \\
\text { show-cased and celebrated. } \\
\end{array}$}} \\
\hline & & & & & & & & & & \\
\hline \multirow[b]{2}{*}{ Workshops } & & \multirow{2}{*}{\multicolumn{3}{|c|}{$\begin{array}{l}\text { Classroom implementation is hindered due to } \\
\text { perception that participants must construct their } \\
\text { own models. Follow-up workshops continue to } \\
\text { focus on improving programming skills. } \\
\text { Curriculum integration issues surface. } \\
\end{array}$}} & \multirow{2}{*}{\multicolumn{3}{|c|}{\begin{tabular}{|l|} 
Focus of summer workshop \\
shifts to curriculum integration \\
and understanding core \\
complex systems concepts to \\
be applied in content areas. \\
\end{tabular}}} & \multirow{2}{*}{\multicolumn{3}{|c|}{$\begin{array}{l}\text { Follow-up workshops focus on developing } \\
\text { curricular units and using existing StarLogo } \\
\text { models and AIM program activities to facilitate } \\
\text { implementation in classroom contexts. Less } \\
\text { emphasis placed on developing programming } \\
\text { skills and constructing new models. } \\
\end{array}$}} \\
\hline & $\begin{array}{l}\text { Strong focus on teaching } \\
\text { participants how to construct } \\
\text { and program their own } \\
\text { StarLogo models. }\end{array}$ & & & & & & & & & \\
\hline \multirow[t]{2}{*}{$\begin{array}{l}\text { Facilitation } \\
\text { Structure }\end{array}$} & $\begin{array}{l}3 \text { instructional facilitators (tier } 1 \text { ) } \\
\text { work with participants during the } \\
\text { summer and follow-up workshops } \\
\text { and in individual classrooms. }\end{array}$ & \multicolumn{3}{|c|}{$\begin{array}{l}\text { Difficulties emerge with centralized } \\
\text { facilitation model due to facilitator } \\
\text { availability and teaching time constraints. } \\
\text { Facilitation model is reviewed. }\end{array}$} & \multirow{2}{*}{\multicolumn{3}{|c|}{\begin{tabular}{|l|}
4 Cohort 1 participants are selected \\
to be tier 2 within school facilitators in \\
an attempt to decentralize facilitation. \\
They become members of the \\
summer workshop instructional team.
\end{tabular}}} & \multirow{2}{*}{\multicolumn{3}{|c|}{$\begin{array}{l}\text { Difficulties with decentralized facilitation model also } \\
\text { occur due to availability and teaching time } \\
\text { constraints. Facilitation model becomes a } \\
\text { combination structure with existing within school } \\
\text { facilitators remaining in tact and } 2 \text { full time non- } \\
\text { teaching facilitators sharing centralized duties. } \\
\end{array}$}} \\
\hline & & & & & & & & & & \\
\hline \multirow[b]{2}{*}{$\begin{array}{l}\text { Curriculum } \\
\text { Development }\end{array}$} & & \multirow{2}{*}{\multicolumn{3}{|c|}{$\begin{array}{l}\text { StarLogo online models library is } \\
\text { developed and released to participants. } \\
\text { (http:/leudcation.mit.edu/starlogo/library) } \\
\text { An idioms programming package is also } \\
\text { developed. }\end{array}$}} & \multirow{2}{*}{\multicolumn{3}{|c|}{$\begin{array}{l}\text { Multi-media case of exemplary StarLogo } \\
\text { curriculum integration and teaching is } \\
\text { constructed and presented to participants to } \\
\text { facilitate classroom implementation. } \\
\text { (http:/leducation.mit.edulaim-cases/index.php) } \\
\end{array}$}} & \multirow{2}{*}{\multicolumn{3}{|c|}{$\begin{array}{l}\text { Binders to be used to hold hard copies of } \\
\text { curricula are distributed. Sample units and } \\
\text { lessons already implemented by participants } \\
\text { are collected and distributed as starter } \\
\text { materials for the curriculum binder. }\end{array}$}} \\
\hline & $\begin{array}{l}\text { StarLogo modeling tutorial is } \\
\text { developed to help participants } \\
\text { construct models. }\end{array}$ & & & & & & & & & \\
\hline
\end{tabular}

\begin{tabular}{l|l}
\cline { 2 - 2 } Communication & $\begin{array}{l}\text { Multiple tools for online communication are used including a bulletin board, email } \\
\text { listserv, and Moodle for reflective journaling. Participants reveal difficulties in }\end{array}$
\end{tabular} Tools keeping track of communication tools.
Communication tools are consolidated into one central website developed with easy interface and full feature set. 
up with detentions and/or staff meetings focused on school improvement. The facilitator with the greatest flexibility in her schedule was the after school program coordinator. She indeed had an enormous impact helping teachers work with their students on AIM activities, however, she was only one person and there were many more teachers who could have benefited from the assistance. To address this issue, the program moved toward a more decentralized facilitation model during the second year of the project in which four Cohort 1 participants became mentors in their own schools as tier 2 facilitators. The hope was that this would alleviate some of the time constraints previously experienced by tier 1 facilitators and that small communities would emerge around a nucleus of like-minded teachers. After some time, we found that, although there was a strong desire to create local community structures, the notion of decentralized facilitation still could not overcome the day-to-day teaching issues such as difficulties in finding common times to meet across different subjects and grade teams. In the Winter '04 and Spring '05 terms, the facilitation structure became a combination model of within school decentralized facilitation accompanied by two centralized non-teaching facilitators who shared classroom visitation and facilitation duties across program schools. This structure appeared to suit the greatest number of participant needs allowing for more informal collaboration between tier 2 facilitators and the teachers in their schools and more formal classroom assistance conducted by tier 1 facilitators.

\section{Curriculum Development.}

Changes made in the curriculum development component are perhaps the most illustrative of how the program continuously adapted to emergent professional development foci. Four curriculum tools were developed over the course of the two-year implementation, each reflecting participant needs at the time of development. As previously discussed, it was determined after 
the first summer workshop that a major barrier to program efficacy was teachers' understanding of StarLogo programming and model construction. In order to assist teachers, one tier 1 facilitator created a comprehensive modeling tutorial and provided pedagogical strategies that would help teachers use the tutorial with their own students. A models library (http://education.mit.edu/starlogo/library) became the next curriculum piece to be developed as participant needs and program foci shifted to curriculum integration. A multi-media case of exemplary StarLogo use in the classroom (http://education.mit.edu/aim-cases/index.php) was also constructed as teachers voiced their concerns about not being able to observe how AIM activities would work in real classroom settings. And finally, the curriculum binder was constructed with ready-to-use sample units parsed into subject content areas and grade levels. It was expected that participants would continue to add lessons to the binder and maintain it for their own purposes. Although the curriculum binder may seem to be a trivial addition, it represented movement toward a more autonomous, self-organized point within the professional development continuum where teachers were poised to take more ownership of their own learning. After each curriculum tool was introduced, participants showed overwhelming interest and used them to more or less degrees in their curricula.

\section{Network Growth}

The focus on creating curriculum tools can also be viewed from the perspective of increasing technological capital, one of the three elements representing network growth in the FANS framework. Identifying human capital also proved to be important in the discussion above on distributing expertise. In this section, additional evidence is presented that demonstrates how successful the program was in improving network growth. Participant comments presented here 
are excerpts from three focus group sessions held during the year-end workshop in the last semester of implementation. 25 Cohort 1 and Cohort 2 participants attended the workshop. Focus group questions solicited opinions about over-all experiences in the project, program factors that influenced success in the classroom and activities that enabled participation in the project.

\section{Technological Capital.}

Several comments were made which related to the important role both curriculum and communication tools developed in the program played in encouraging participation.

Jerry: The discussion forums [on the central project website] were good. I didn't do a lot of posting but lots of reading. It was really cool to tap into other brains. I posted something about an interest I had and instantly, Henry, across the country responds with models and ideas that he used. That's a useful resource-it's there if you want it or need it.

Tal: The quality of the work, the games and challenges, the website [were helpful]. You can see the models and create other programs with existing ones. And like any language, there are immediate outcomes.

John: A factor [at our school] for the two teachers using the palm pilots was that they had them there. Dee went to get cords to keep the palms charged which was very helpful. It was a whole lot easier having them there if they wanted to do something spur of the moment or if they needed to rearrange their schedule. 


\section{Human Capital.}

Numerous other participant comments pointed to the importance of being able to draw on facilitator experiences and skills as well as those of other participants in the project.

Debra: My experience was exceptionally good because during summer session I met Mark so then he was hired to work at Secondary and that's 95\% of the reason that my experience has been so positive because he is someone who is a technical person who could help me from buying computers in August to making sure they were all set up, showing us how to use the projector that we bought-just everything. We kept it simple and it worked all year.

Bobby: The facilitators...I could rely on Sara or Dean if the palm pilots were not working or to look at my code if the model wasn't working.

Janet: Right the palms. I just can't believe how easy it's been to get palms from Sara. The availability of palms and facilitators [is great]. The biggest thing is that facilitators are teachers and share the same language. We're all together.

\section{Social Capital.}

Perhaps the greatest contributor to network growth was evident in the kinds of social links and attachments to both local and broader educational community structures participants made throughout the course of the program. 
Liz: ...As part of the work with AIM and AiSC [Adventures in Super-Computing], I've become nicely connected with people at the State Department of Education and they approached me after the AIM event on Tuesday to see if we'd be interested in working with them to develop some modeling to go with the standards statewide.

Janet: It's been a really good experience. I've really enjoyed getting back together with everybody and it seems to come at the time where I've hit the lowest part of the profession during the year and it's a nice shot in the arm, getting back with colleagues, having real conversations, just being able to share things that aren't necessarily SL but the system that we're working in. As PD it's really helped me because it's part of my PD plan to work outside of the school to work with professional community more broadly to think about how can we work and change the system. Just by having the support helps to keep my focus and helped me attain some of my goals.

As a measure of program efficacy, collectively, the evidence presented to illustrate network growth, shows a strong and continually developing professional development program. Not documented here, is the overwhelming feeling of community (further discussed below) participants demonstrated in informal discussions with program facilitators and researchers. Participants also often commented, during workshop debriefs, that one of their main professional development goals (as written in their yearly PDPs or professional development plans) was to spread the word about the AIM program within their school and bring other people into the community. 


\section{Self-Organization}

Although self-organization, as we interpret it in the FANS framework, is best understood when sufficient time has passed that strategies explicitly used to encourage self-organization can be evaluated, there is some evidence to suggest that the long-term goal of adoption of program ownership was happening by the end of the second year of the program. In this section, evidence of self-organization along several parameters, taken from discussions in the final workshop focus group sessions, is presented.

\section{Professional Goal Setting.}

A number of comments made by participants showed that program flexibility enabled teachers to set their own professional development goals which, in turn, appeared to inspire confidence to set more long term goals or add more program activities to their repertoire. The following examples illustrate this point.

Jerry: ...Particularly this year because this was my first year teaching US history, new concepts and events, it's May and we're talking about the American Revolution so you get a sense of how far behind I am. That's the thing, you've got to find the concept and application that meet the two criteria: efficacy and effectiveness. Need to figure out where the time is best used by StarLogo-not a barrier but a challenge that you have to struggle with. I've put myself on the three-year plan and hopefully in 3 years I'll be using this efficiently and effectively.

Barry: It kind of tells me what I'd like to be doing better. It shows the opportunities out there. With the background preparation and the support people so it doesn't flop on you. I hadn't had 
the nerve to bring in the palm pilots. I had this vision of them disappearing or flying across the room. I've been very leery about how much I can trust the students with those little gadgets so it's figuring out how to make it work and then seeing the potential of what it can do. So I still see it as something of an opportunity for me. It gets me focused on the future of education instead of what I'm doing right now.

\section{Community.}

Also related to increases in social capital, the importance of the strong professional community from which strength, reassurance and new ideas could be drawn, emerged as an important theme for self-organization.

Val:...For me in the second year, time is always a problem to do a long in-depth program. But one of the great things is just idea generation and seeing and hearing how other people's experiences have gone. I haven't done any [of the Participatory] Simulations, but a lot of StarLogo, and next year I'll bring the simulations in. I've hesitated because of how much set up but it sounds like one of the things that's been successful is the lack of set up and that's good. If I hadn't heard from others who've implemented in the classroom, I'd be less likely to do it.

Mark: I would rate [this program] a 10 for lots of reasons. The reason I'm thinking about at the moment is that there's lots of community and support available. There've been moments where I've been having some doubts about things... is this going to work... but every one of those moments, I've had facilitators... someone from the program that I can rely on to share ideas, to help me out, and that's the biggest strength of the program. I mean the technology's great. The 
kids are engaged. They seem to be learning a lot, but to make it work you have to have community. Without that, it will sputter.

\section{Individualizing Purpose.}

Increasing teacher personal autonomy and empowerment is a critical component of selforganization as it has been defined in the FANS framework. To that end, many comments illustrated the sense of individualization of purpose participants experienced and defined throughout the program.

Janet: I have the information and I constantly think of my students as a complex system. I remember the ball bearings [a demonstration of complex systems behavior] and I think about my particularly trying individuals in the classroom and trying to severe that weird energy in the classroom, that they just end up linking back some how. So trying to take that energy and how to redirect. So for me it's been more philosophical rather than using the activities or models.

Jerry: Since I came in I didn't try to tell myself that I would do tons of StarLogo. I figured what I would do, would be fairly minimal or small and that's what I did. Overall, my success matched my goals so my experience overall was really good but overall I think the program, the whole experience, it's all good stuff. I always walk away feeling 10 times more energized then that Friday or week beforehand. Good stuff. What I did do was very successful (the palm simulations) but holy cow, what a transformative experience in the classroom. That definitely gives a boost for doing more later on. 
John: Aside from all the pedagogical aspects, from a totally selfish point of view as a selfeducated programmer myself, to learn a language and to work in a community has been a life changing experience for me. I love working with SL. I speak three other computer languages and I haven't touched any of them since I started with SL. I want to do SL. Just recreationally it's been very rewarding. There have been times when I feel that nothing in my life is going right and I can sit down and write code. I can email someone and say how did you do such and such and get an answer back and we move along. That kind of thing has helped me immensely in how to think, keep my brain awake.

It is important to reiterate here that participants in the focus group sessions were from two consecutive cohort years. Teachers who had followed through in the program for a second year such as Barry, Janet and John clearly saw value in the program in terms of not only addressing current pragmatic teaching issues but also in encouraging philosophical and personal shifts that are likely to continue to impact their professional growth for some time to come. In the following section, we hypothesize a meta-level set of themes that may account for the success of the FANS framework in all four of the design principle categories.

\section{DISCUSSION}

In a recent convening of leading educational technology researchers at Harvard, Dede \& Honan (2005) conclude that four common themes unify efforts to scale up successful educational innovations: coping with change; promoting ownership; building human capacity; and effective decision making. Reiser et al. (2000) have written about the importance of attending to the mutual adaptation of research goals and local contexts in order to support educational reform 
efforts. Fishman et al., (2004) present a list of key issues to explore when dealing with technology innovations and the capacities of the educational contexts the technologies are intended for. These include: teacher learning; assessment; planning for technology and organizational structure and leadership. Not coincidentally, the professional development framework we have constructed, implemented and evaluated in this paper overlaps with the above research in many fundamental areas primarily because, despite differences in methodology, we all aim to understand and improve the complex system that is the educational system we work within. What we have offered is a complex systems framework that has practical implications for professional development efforts in a number of different ways. When looking across the evidence, several meta-level themes, also rooted in a complex systems explanation, can be hypothesized to account for the success of the FANS framework. A discussion of these themes, follow in this next section.

\section{Structure vs. Agency}

The tension between structure and agency is an essential characteristic of real world complex systems. As Watts (2003) notes, "It is through our surrounding structure that we order and make sense of the world. Yet too much structure, too strong a hold of the past on the future, can...be a bad thing, leading to stagnation and isolation” (p. 100). Ensuring a balance between structure and agency appeared to be a critical enabling component of our professional development framework. Structure can be interpreted in at least two ways, i.e., the structure of professional development activities and the educational structure as outlined in the topology of implementation variables (Table 2). Similarly, multiple levels of agency exist in the program, i.e., individual participant personal and professional agency, facilitator/researcher agency, a 
collective group agency as educators in our distinct community or educators within the more global educational system. It is hypothesized that the success of the FANS framework can in part be attributed to our ability to manage the delicate tension between structure and agency. Understanding the context within which we operated through feedback - the physical barriers such as centralized computers, broader educationally imposed barriers such as NCLB and the like, then applying this information to promote adaptation, increase network capital and support self-organization facilitated a constant development and exchange between structural (e.g., construction of curricular tools) and agency-related (self-efficacy beliefs) variables.

\section{Exploration vs. Exploitation}

Axelrod and Cohen (1999) write about an important trade-off principle of exploration vs. exploitation when applying interventions to complex systems. This trade-off principle is referred to as exploration versus exploitation. Exploration activities include those that bring in new information, knowledge and/or skills. Exploitation activities include those that explore the new information, knowledge and/or skills in the context within which they are applied. Similar to structure and agency, striking a balance between exploration and exploitation serves as an important mechanism for ensuring that a great deal of time is not wasted implementing exploration activities that will have no net effect on growth or be of little value to the system, and for ensuring that premature adoption or rejection does not occur due to insufficient understanding of the effects of the new intervention within specific contexts. The trade-off principle was indeed manifested in several ways over the two documented years of the program. For example, due to the open-ended flexible nature of the tools, curriculum and facilitation supports, teachers were afforded opportunities to set their own professional goals, create 
individualized purposes and draw on the evolving community of practitioners for different reasons. In other words, they were able to exploit the program to suit their own needs while at the same time exploring new methods and philosophies of teaching and new ways of looking at the world through a complex systems lens. Likewise, as seen primarily in the principle of adaptation, the evolution of the scope and sequence of events in all seven professional development categories can be thought of as being premised on an exploration/exploitation evaluative cycle, i.e., develop and implement the strategy, assess its efficacy and revise current strategy or implement a new one.

\section{Short-term vs. Long-term Goals}

The last meta-level theme we wish to reveal relates to differences in time scales and viewing program decisions and outcomes from the perspective of short-term and long-term goals. Lemke (2001) presents a model for understanding multi-scale complex systems that is premised on interpreting processes and activities that occur within and between different levels of organization. He suggests that how we come to understand the meaning of something is often contingent on the accumulation and transfer of information, acquired through short-term events, that may be distant from each other in space and time. Thus, we must be cognizant of the notion that change can happen over shorter and longer periods of time. He also states, "To analyze human social activity, development and learning across multiple time scales, we must be as willing to look at biography and history as at situations and moments, as methodologically and theoretically prepared to study institutions and communities as to study students and classrooms” (p. 25). In Table 1, we presented a topology of implementation variables that include biographical and historical information (e.g., previous career experiences) as well as contextual 
or environmental information that potentially impacts the success of the program. These implementation variables have also been analyzed to take account of the multiple levels of systems we work with. But perhaps the greatest use of the topology that we have found has been as a tool for setting short-term and long-term program goals as well as for understanding shortterm and long-term participant goals. Identifying hierarchies of change and determining which variables were the most feasible to address at different times, provided the project team with a manageable structure from which to proceed toward positive project development. Likewise, providing enough flexibility and acknowledging that participants spontaneously self-organized to find individual utility from program activities has helped us to set realistic short-term and longterm goals which has in turn fuelled our optimism in the program's efficacy.

\section{CONCLUSION}

The purpose of this paper was to demonstrate the efficacy of a professional development framework informed by the four complex systems design principles of feedback, adaptation, network growth and self-organization. We have shown that structuring a professional development program around the FANS framework facilitates the development of important strategies and processes for program organizers such as the identification of salient system variables, effectively distributing expertise, adaptation and improvement in professional development resources and activities and building technological, human and social capital. Perhaps more importantly, for the participants, there is evidence to show that the FANS framework encourages: professional goal setting, engagement in a strong professional community and personal autonomy by enabling individualized purpose-all fundamental components in promoting self-organization. We also hypothesize three meta-level themes that 
may account for the success of the FANS framework. Each illustrates the tension that exists between competing variables that need to be considered in order to work effectively in real world complex educational systems. We believe that FANS offers a tenable framework for achieving scalable enduring curricular and pedagogical reform and will continue to measure and report on program efficacy with respect to these four important design principles.

\section{ACKNOWLEDGEMENTS}

We would like to gratefully acknowledge Judy Perry for her assistance on the data analysis portion of this paper. This research was supported by a National Science Foundation ITEST Grant (Award \# 0322573).

\section{REFERENCES}

Arrow, H., McGrath, J. \& Berdahl, J. (2000). Small Groups as Complex Systems. Formation, Coordination, Development and Adaptation, Sage Publications, Inc., Thousand Oaks, CA.

Axelrod, R. \& Cohen, M. (1999). Harnessing Complexity, The Free Press, New York

Bar-Yam, Y. (1997). Dynamics of Complex Systems, Addison-Wesley, Reading, Mass.

Capra, F. (1996). The Web of Life, Bantam Doubleday Dell Publishing Group, Inc., New York.

Coburn, C. (2003). Rethinking scale: Moving beyond numbers to deep and lasting change. Educational Researcher 32(6): 3-12.

Colella, V. \& Klopfer, E. (2000). Seeding change: Bringing modeling to science teachers and their students. The Bulletin of The Santa Fe Institute, 15(2).

Colella, V., Klopfer, E. \& Resnick, M. (2001). Adventures in Modeling, Teachers College Press, New York.

Cuban, L., Kirkpatrick, H. \& Peck, C. (2002). High access and low use of technologies in high school classrooms: Explaining an apparent paradox. American Educational Research Journal 38(4): 813-834. 
Dede, C. \& Honan, J. (2005). Scaling up success: A synthesis of themes and insights. In, Dede, C., Honan, J. \& Peters, L. (Eds.), Scaling Up Success: Lessons Learned from Technology-Based Educational Improvement, Jossey-Bass, San Francisco, CA, pp. 227-239.

Elmore, R. (1996). Getting to scale with good educational practice. Harvard Educational Review 66(1): 1-26.

Fishman, B., Marx, R., Blumenfeld, P., Krajcik, J. \& Soloway, E. (2004). Creating a framework for research on systemic technology innovations. The Journal of the Learning Sciences 13(1): 43-76.

Fullan , M. (1993). Change Forces: Probing the Depths of Educational Reform, The Falmer Press, London.

Fullan, M. (1999). Change Forces: The Sequel, The Falmer Press, London.

Fullan, M. (2003). Changes Forces: With a Vengeance, RoutledgeFalmer, London.

Gell-Mann, M. (1994). The Quark and the Jaguar, W. H. Freeman and Company, New York.

Goldman, S. (2005). Designing for scalable educational improvement. In, Dede, C., Honan, J. \& Peters, L. (Eds.), Scaling Up Success: Lessons Learned from Technology-Based Educational Improvement, Jossey-Bass, San Francisco, CA, pp. 67-96.

Hmelo, C., Holton, D. \& Kolodner, J. (2000). Designing to learn about complex systems. Journal of the Learning Sciences 9(3): 247-298.

Holland, J. (1998). Emergence: From Chaos to Order, Helix, Reading, MA.

Johnson, S. (2001). Emergence: The Connected Lives of Ants, Brains, Cities, and Software, Simon \& Schuster, New York.

Klopfer, E. Yoon, S., Perry, J. (2005). Using palm technology in Participatory Simulations of complex systems: A new take on ubiquitous and accessible mobile computing. Journal of Science Education and Technology 14(3): 285-298.

Lemke, J. (2001). The long and the short of it: Comments on multiple timescale studies of human activity. Journal of the Learning Sciences 10(1\&2): 17-26.

Liljenstrom, H. \& Svedin, U. (2005). Micro Meso Macro: Addressing Complex Systems Coupling, World Scientific Publishing Co., Inc, London.

Lincoln, Y. S. \& Guba, E. G. (2000). Paradigmatic controversies, contradictions, and emerging confluences. In, Densin, N. K. \& Lincoln, Y. S. (Eds.), Handbook of Qualitative Research, Sage, Thousand Oaks, CA. 
Putnam, R. (2000). Bowling Alone, Simon \& Schuster, New York.

Reiser, B.J., Spillane, J. P., \&Steinmuller, F., Sorsa, D., Carney, K., \& Kyza, E. (2000). Investigating the mutual adaptation process in teachers' design of technology-infused curricula. In, Fishman, B. \& O’Conner-Divelbiss, S. (Eds.), Fourth International Conference of the Learning Sciences, Erlbaum, Mahwah, NJ, pp. 342-349.

Senge, P., Cambron-McCabe, N., Lucas, T., Smith, B., Dutton, J. \& Kleiner, A. (2000). Schools that Learn, Doubleday, New York.

Sterman, J.D. (2000). Business Dynamics: Systems Thinking and Modeling for a Complex World, The McGraw-Hill Companies, Boston.

Strauss, A. L. \& Corbin, J. M. (1998). Basics of Qualitative Research: Techniques and Procedures for Developing Grounded Theory $\left(2^{\text {nd }}\right.$ edition), Sage, Newbury Park, CA.

Varela, F. (1999). Ethical Know-How: Action, Wisdom, and Cognition, Stanford University Press, Stanford, CA.

Watts, D (2003). Six Degrees, W. W. Norton \& Company, Inc., New York.

Yi-Zhang, T. \& Kim, J. (2005). Macro-, Meso-, Micro- and Nano-Mechanics of Materials, Trans Tech Publications Inc., Zurich. 